\title{
Integrating niche-related and general process approaches in the study of learning
}

\author{
William Timberlake \\ Department of Psychology, Indiana University, Bloomington, IN 47405, USA
}

Accepted 5 January 2001

\begin{abstract}
For nearly a century the experimental analysis of learning in animals has been divided into niche-related and general-process approaches, each emphasizing different procedures and conceptual strategies. After considering several current forms of rapprochement, I outline evidence for the integrative hypothesis that niche-related learning provides the basis for results in traditional general-process learning paradigms. Although the full ramifications of this view are not developed here, its advantages include: a clearer relation between laboratory and field results; conceptual and pragmatic guidance in developing new paradigms, and applying old ones to different species and circumstances; clarification of the laws, limits, and anomalies in general-process paradigms; and a more efficient path for inter-relating the study of learning with neurophysiology, genetics, and evolution. (C) 2001 Elsevier Science B.V. All rights reserved.
\end{abstract}

Keywords: Learning; Animals; Evolutions

\section{Introduction}

The heyday of natural history in Europe during the latter half of the 19th century (Barber, 1980; Galef, 1988) was accompanied by strongly anthropomorphic interpretations of the causation of learning and behavior in animals. Naturalists reported their observations as though animals were human acquaintances disguised in feathers and fur. If male and female great-crested grebes behaved in a way that reminded J.S. Huxley (1914) of starry-eyed human lovers, he did not hesitate to assume that similar feelings and beliefs motivated the behavior of both the species. Likewise, if a bird sang robustly at dawn and dusk, Selous
(1931) claimed it was valiantly declaring love for its mate for the enjoyment of its human audience.

This unbridled invocation of human-centered interpretations of animal behavior compared poorly with both the rigorous observations of field biologists and geologists (Eiseley, 1961) and the careful methods of medical physiologists in analyzing the phenomena related to nerve conduction, sensory reflexes, and disease. This contrast helped set the stage for the emergence of a small contingent of researchers interested in combining careful observation with an experimental analysis of the role of experience in determining that behavior. For example, Douglas Spalding (Spalding, 1872) determined the temporal course of the ten- 
dency of young chicks to imprint on their mothers by depriving them of vision for different periods of time. John Lubbock (Lubbock, 1882) showed that ants and caterpillars used scent rather than vision or touch to follow each other. C. Lloyd Morgan (Morgan, 1895) showed that a young chick's single experience with a bad tasting cinnabar caterpillar produced avoidance and disgust reactions to the sight of the caterpillar.

\section{Divergence}

Although influential, this convergence in how to study learning and behavior in animals was short-lived. Emerging research traditions in behavior-oriented biology on one hand and experimental psychology on the other soon diverged in how experiments were designed, performed, and interpreted. The biological tradition, heavily influenced by ethology and its precursors, treated learning as one potential contributor to the control of everyday niche-related behavior in the animals they observed. In contrast, experimental psychology, especially in America, focused on the isolated laboratory study of learning by animals domesticated as subjects. Using standardized and highly controlled conditions, experimenters searched for general learning processes and laws that would characterize the behavior of all creatures in any circumstance.

For over a century, the split between niche-related and general-process approaches to the study of learning has proved as persistent and influential as the more widely cited differences between cognitive and behaviorist approaches. Differences between the niche-related and general-process approaches have contributed to both historical and current conflicts, including: the sometimes acrimonious struggle between ethologists and comparative psychologists about how to analyze and talk about behavior (Lehrman, 1953; Lorenz, 1965); the still simmering debate over the nature and importance of predispositions and constraints in learning; and the recent conflict over anthropocentric versus ecological approaches to cognition (Shettleworth,
1998). At the turn of a new century it seems appropriate to consider again the nature of these two approaches and how they might be combined to produce an integrated study of learning.

\subsection{Niche-related approach}

Elements of the niche-related approach are illustrated in Tinbergen's (Tinbergen, 1951) study of the provisioning of offspring by digger wasps. Combining observation of free-ranging wasps with simple experimental manipulations, he was able to reveal an important contribution of learning to the wasp's behavior. By changing local landmarks, Tinbergen showed that when a wasp departed on a hunt from a recently dug nest, it entered in memory the spatial relation of the burrow entrance and the surrounding landmarks to guide its return. This niche-related approach embeds learning in the ecologically relevant behavior of an animal, emphasizing the evolutionary basis of specific adaptations and stimulus-response mechanisms and their occurrence within functional regulatory systems, such as feeding or defense (Timberlake, 1993).

An advantage of the niche-related approach is that its specificity in terms of perceptual-motor structures and motivational processes has promoted neurophysiological and developmental analysis of particular sets of underlying mechanisms. Further, the focus on adaptive mechanism has promoted genetic, comparative, and evolutionary research related clearly to the natural behavior and ecology of a species. For example, consider the progress made in establishing the specific neurophysiological and endocrine circuitry involved in the development, acquisition, production, and selection of components of bird song (e.g. DeVoogd and Szekely, 1998). Comparative research on bird song learning has been able to focus on similarities and differences among species that are phylogenetically and/or ecologically related (also see Kroodsma, 1988), leading researchers to hypotheses about the course of evolution of song learning and production in birds. 


\subsection{General-process approach}

In contrast to the niche-related experimentation favored by field biologists, a different sort of experimentalist fervor swept American psychology near the beginning of the 20th century (Galef, 1988; Timberlake, 1983b). Not only were psychologists primarily interested in isolating the study of learning from the complications of everyday behavior, they became increasingly concerned with studying learning de novo and in the abstract, separated from the context of ecologically-relevant stimuli and responses. Artificial learning problems were instantiated in novel circumstance using stimuli and responses that were not an overt part of the animal's instinctive repertoire. In this way researchers hoped to establish and test general laws that could be generalized to all organisms in all settings (Thorndike, 1911).

The general-process approach was given an early boost by the translation of Pavlov's (Pavlov, 1927) work on the conditioning of digestive reflexes in dogs and the development of increasingly standardized experimental paradigms, defined by particular combinations of apparatus, procedure, reward type, and species. In each paradigm the manipulations and measures were related to abstract variables defined by the experimenter with primary concern for their accuracy and reliability rather than their relation to the everyday functional behavior of an animal. Thorndike (1911) developed one of the first experimental paradigms in his work with hungry cats confined in a 'puzzle box' from which they escaped to find food by performing an arbitrary response, such as turning a latch or pulling a string loop. His index of learning was the decrease in latency of escape over trials.

The general-process approach has the advantage of contact with a large amount of research using common paradigms and a general way of conceptualizing learning. Applied work in human and non-human animals has successfully borrowed procedures from the general-process approach. However, the focus on generality also has its costs. At the neurophysiological level, modern investigators usually neglected specialized sensory-motor circuitry in studying learning in favor of looking for central, more general reward pathways and memory locations, where progress has been slower. Thus, although Lashley (1950) began looking for the learning engram in the 1920s and Olds and Milner (1954) established the possibility of a common brain substrate of reinforcement in the 1950s, the most rapid progress in studying the neurophysiology of learning has come in the analysis of specialized circuitry, such as that as found in rabbit eyelid conditioning (Steinmetz and Thompson, 1991). In terms of evolution, comparative research in the general-process tradition has been forced toward the 'protoevolutionary' (Timberlake and Hoffman, 1998), that is, based on the scaling of unrelated species according to their ability to perform on standardized problems rather than on tracing the natural selection of learning among phylogenetically related and/or ecologically convergent species.

\section{Rapprochement}

The premise underlying this paper is that the study of learning can profit from the integration of niche-related and general-process approaches. Not only has a good deal of effort been expended on the unresolved conflicts mentioned above, but also the strengths of the two approaches appear potentially complementary. The general process approach supplies tools to explore and analyze the flexibility of stimulus control, response form, and the contribution of environmental support (e.g. Timberlake, 1994). It also provides an abstract causal schemata that can be used to categorize problems and suggest applied possibilities in human and non-human animals. The niche-related approach focuses on specific functioning and adaptation that encourages contact with the everyday behavior of an animal in its niche and clarifies how it interacts with laboratory apparatus and procedures. It also particularizes the study of learning in a way that can promote contact between behavior and neurophysiology, evolution, and genetics.

Fortunately, several developments in the last 25 years have led to rapprochement between (although not integration of) the niche-related and 
general-process approaches. I will consider briefly three such forms of rapprochement below. In the next section, I will examine support for a new form of rapprochement that I think shows promise for an integration of the two approaches.

\subsection{General-process learning laws as explanations of niche-related learning}

The oldest form of rapprochement is based on the assumption that niche-related learning is ultimately based on general-process mechanisms and laws. For example, when Lorenz (1937) and Hess (1964) claimed that the characteristics of imprinting in birds differed from those evinced in examples of traditional laboratory learning paradigms, the implied challenge to the universality of general-process results was quickly addressed. Researchers like Hoffman (1977) argued that the same general processes that produced maze learning and lever pressing in rats also produced imprinting in ducklings. In the 1970s and 1980s similar arguments were made about the ability of general process laws to account for niche-related learning phenomena such as taste aversion learning (e.g. Logue, 1979; Krane and Wagner, 1975).

In a variant of this approach, a number of psychologists have compared the outcomes of using Pavlovian or operant conditioning procedures to explore an example of niche-related learning with the traditional phenomena found in common general-process paradigms. For example, Bitterman and his colleagues have spent a number of years establishing the extent to which unconstrained foraging bees show learning phenomena similar to those shown by rats in a variety of general-process learning paradigms. Thus, bees show blocking and overshadowing effects, but not the partial reinforcement extinction effect. Similarly, Kamil and his coworkers, after establishing niche-related species differences in food-storage memory in corvids, sought to provide parallel evidence of species differences in the general process memory paradigm of delayed matching to sample.

On a more modest scale, both comparative psychologists and biologists have suggested that specific laboratory phenomena can be viewed as explanations for particular examples of niche-related learning. For example, Vos (1995) attributed color preferences in mate selection by male zebra finch to the peak shift phenomenon shown in laboratory examples of discrimination learning. van Kampen and de Vos (1995) showed the laboratory-derived phenomena of blocking and overshadowing occur in imprinting.

A general limitation on the contribution of this type of rapprochement to an integration of the two approaches is that its focus is on discovering similarities between niche-related learning and learning in general process paradigms, rather than on a more careful analysis of the determinants of either. As a result the interpretation of documented similarities and differences is often unclear. For example, if partial reinforcement occurs in rats but not in bees but blocking occurs in both, it is not clear how this should be interpreted or what experiments should be done next. Similarly, if peak-shift can explain mate choice in male zebra finch, that should not be the end of the story as the parameters and mechanism of peakshift itself are not well understood.

\subsection{The addition of laboratory techniques to the study of niche-related learning}

In this form of rapprochement researchers have worked to apply the power of laboratory techniques to the study of niche-related learning. For example, psychologists such as Alan Kamil, Sara Shettleworth, and David Sherry and biologists like Russ Balda, John Krebs, and Nikki Clayton developed ways to isolate and analyze important elements of food storage and retrieval in birds using controlled artificial versions of naturally occurring circumstances. Kamil and Balda studied elements of food storing in corvid species, especially Clark's nutcracker, in laboratory settings ranging from open fields to radial arm mazes. Shettleworth, Clayton, Krebs, and Sherry administered daily trials by releasing birds into rooms containing artificial 'trees' with Velcro-covered food holes drilled into the wood or feeding stations hung on a wall.

The results of these experiments have allowed precise analysis of the cues controlling food stor- 
ing, and have prompted neurophysiological work outlining the pathways, structures, and processes involved not only in food storing, but also in how birds generally find their way about the environment (Bingman and Jones, 1994). As a path to integration, though, a drawback of this approach is that it has focused on more careful investigation of niche-related learning, rather than on improving our understanding of learning in general-process paradigms.

\subsection{Niche-related learning as classes of cognitive process}

A recent form of rapprochement is based on classifying learning using information processing labels related to human processing. Authors of recent learning textbooks (Pearce, 1997; Roberts, 1997; Shettleworth, 1998; following Gallistel, 1990, book) have put together niche-related and general-process research in chapters dedicated to classes of cognitive processes, such as navigation, counting and timing, causal perception, spatial representation, memory, and discrimination/categorization. An advantage of using informationprocessing labels from the study of human cognition is the encouragement to use the same procedures to study both human and non-human examples. For example, Wasserman (1993) and his students have extensively studied the memory and categorization capabilities of pigeons using procedures and models based on human experiments.

As a basis for integration, a disadvantage of this view is that using the same cognitive labels to describe both general-process and niche-related phenomena leads to the assumptions that the phenomena and processes are understood and identical in humans and other animals (e.g. Griffin, 1981). In practice, both the distinctions and commonalities among forms of cognition remain unclear. Further, labeling all learning as cognitive excludes contributions from learning researchers who do not view themselves as studying animal cognition. Equally importantly, it is not clear that all forms of learning are most effectively viewed through a cognitive lens.

\section{Niche-related learning in general-process paradigms}

In this section, I consider a relatively novel approach to the integration of niche-related and general-process learning, which is based on the hypothesis that niche-related learning is a basic component of general-process paradigms. An initial argument against this view is that because aspects of niche-related learning can be modified by traditional learning procedures, niche-related learning must be subsumed under general-process laws. However, that niche-related learning can be modified by traditional laboratory procedures does not require the conclusion that general-process learning forms the basis of niche-related learning. For example, that species of food-storing birds can solve radial arm mazes, or be shaped to store food in particular arbitrary locations, or show memory differences in laboratory tasks does not entail that general learning processes generate the basic phenomena of food storing and retrieving. The most careful way of summarizing the data, is that, general process and niche-related learning can be viewed as sharing common aspects. For my purposes here, the most interesting way of considering the matter is the hypothesis that niche-related learning provides the basis of learning in traditional paradigms. This possibility is worth considering because to the extent it is supported it allows researchers to view laboratory and niche-related learning within a single ecological framework, thereby promoting the integration of general process learning with the commonly explored determinants of niche-related behavior, including evolution, genetics, development, and neurophysiology.

In the next three subsections I briefly consider three types of evidence relevant to the view that general process learning paradigms (combinations of apparatus, procedure, reward, and species) are related to niche-related learning. One type of evidence consists of a brief survey of face-valid niche-related aspects of common general-process paradigms. A second type of evidence is based on clarifying a means by which niche-related contributions to common laboratory paradigms could have emerged within a general process approach 
that self-consciously emphasized the artificial qualities of its apparatus and procedures. A third type of evidence is based on evaluating several niche-related predictions about characteristics of learning in general-process paradigms.

\subsection{A brief survey of face-valid niche-related aspects of general-process paradigms}

Since the abstract language used to describe general process learning theories, laws, and hypotheses is not obviously niche-related, it follows that any niche-related aspects present must be embedded in the procedures and apparatus of the experimental paradigms. Thus, our first consideration is whether standard general-process paradigms such as puzzle box behavior in cats, maze learning in rats, keypecking in pigeons, and leverpressing in rats are tied to common niche-related problems and make use of naturally occurring perceptual-motor structure and motivational processes.

At first glance Thorndike's (Thorndike, 1911) work with cats in 'puzzle box' cages has little to do with niche-related issues. In fact, he took pains to point out that he chose this task for its artificial qualities, specifically avoiding rewarding any behavior that occurred as part of the cat's initial instinctive reactions of clawing, scratching, squeezing, and mewing. Instead, Thorndike rewarded human-related responses such as pulling a ring, turning a latch, or pushing against a pole. However, there are several reasons to suppose these responses are related to niche-typical repertoires engaged by the experimental circumstances. For example, we know from the observations of Moore and Stuttard (1979) that cats in a puzzle box can displace poles by rubbing against them, a social response in the presence of familiar humans associated with feeding. Like many other observers, I have seen cats repeatedly prey on and capture objects that mimicked only the movement of prey by hooking pulling, and turning them with a combination of paws and extended claws. This behavior appears close enough to Thorndike's food-rewarded responses to suggest a connection between his responses and the cat's repertoire associated with imminent feeding.
In contrast, Willard Small (Small, 1900), inventor of the Hampton Court maze, stated that he got the general idea of using a maze-like environment for studying learning in rats when he helped repair the floor of a beach house and found underneath it a series of maze like passages developed by local rodents. Small (1900) promoted the maze as an example of a learning apparatus that fit the 'psychobiological' character of the subject. Subsequent work on spatial learning in rats has done nothing to detract from Small's general recommendation about designing the apparatus for the psychobiological character of the subject, nor from his specific conclusion that rats should do well in maze studies. Observations like those of Calhoun (1962) made clear the importance of pathways in the everyday life of a free-roaming rat, and the historical persistence of maze studies argues we are dealing with an apparatus particularly suited to rats. However, references to the niche-related character of the maze virtually disappeared.

A related account seems possible for key pecking in pigeons. Pecking is both an appetitive and a consummatory behavior that normally-reared pigeons use extensively when searching for and ingesting food. It is a complex behavior based on a series of perceptual-motor mechanisms that have elicited, predictive, and outcome-related aspects. Pecking is integrated into feeding by the experiences of young squab with parental grain feeding and crop feeding in young squab during the transition from parental feeding to independent foraging (Balsam et al., 1993). It seems relevant that pigeons like other grain-feeding birds direct pecks at small objects, and that they acquire keypecking for food more readily if there is a small dot about the size of a food grain on the lighted key. Pigeons also will peck a small (but not a large) lighted key that is periodically paired with food, even if by pecking the key the food is delayed or omitted (Hearst and Jenkins, 1974; Williams and Williams, 1969). Moore's (Moore, 1973) work demonstrating different forms of key contact as a function of water vs. food reward is also worth noting.

Seemingly the only lack of clarity in a niche-related account of keypecking is why pigeons learn 
to peck keys located at head-height on a wall at least as readily as they peck keys lower on the wall or located on a low 'stand' off the floor. Timberlake and Lucas (1985) in our work on the superstition paradigm proposed that the dominant responses of pressing against the wall and head bobbing in the absence of overt predictive stimuli could provide a ground for keypecking, especially because it appeared related to early niche-related behavior of begging crop-milk and food from adults. In support of this proposal, we have shown that ring doves (a congener of pigeons also feeding crop milk) show similar walldirected 'superstitious' behavior, while chickens show scratching and pecking the floor.

But what of lever pressing in rats? There are no levers in the wild, and rats do not usually appear to be opening a lever as if it were a seed or capturing the lever as though it were a prey item (although, see Peterson et al., 1972). If lever pressing was related to responses normally part of the foraging repertoire of rats, then we would expect to see identifiable portions of the food repertoire directed to the lever. In fact, my own experience with attempting to build movable levers for rats from 'scratch' revealed many such responses. Instead of the rats' nicely manipulating the lever (as I had seen in movies of lever pressing in skinner boxes), variation was the rule. The rats nosed and nudged under the lever, reared and investigated over it, chewed it, tugged at it, held it, shook it, and in general treated it with a repertoire of behaviors suitable for finding, capturing, and consuming food, (see also Muenzinger's, (Muenzinger, 1928), lever pressing work revealing the foraging repertoire of guinea pigs, and Stokes and Balsam, 1991).

In short, a brief and cursory review of common general-process learning paradigms provides surprising support for the hypothesis that they are based on a foundation of niche-related learning and behavior. The combinations of apparatus, physical and sensory capabilities of a species, and the procedures that characterize traditional general-process paradigms appear to be anything but arbitrary and artificial.

\section{Contributions of tuning to niche-related learning in general-process paradigms}

But how could such niche-related aspects of particular species have become embedded in general-process paradigms? Nearly all the well-known experimenters emphasized the artificial and interchangeable nature of the responses and stimuli used in traditional paradigms (e.g. Hull, 1943; Skinner, 1953; Thorndike, 1911), yet (as we have just seen) there appear to be important nonarbitrary aspects of the dominant general-process paradigms. I believe a good portion of the answer to this puzzle lies in the practical talent shown by experimentalists in tuning these paradigms. By tuning I mean that experimenters chose and iteratively modified the environment, stimuli, manipulanda, reward contingencies, measurement procedures, and setting conditions to increase the vigor, reliability, and interpretability of resultant responding. My argument is that increases in these response characteristics occur because the experimenter gradually discovers circumstances that approximate key niche-related characteristics for the species under study.

What is the evidence that such tuning has actually occurred? Besides Small's (Small, 1900) pioneering statement about fitting his apparatus to the psychobiological character of the subject, there are few direct discussions of tuning, but much indirect evidence that it occurred. To his credit, Skinner (Skinner, 1938, 1959) provided several explicit accounts of tuning in rats (although he highlighted the importance of his own laziness as a motivation for tuning rather than the resultant vigor and interpretability of responding that he attended to). For example, in The Behavior of Organisms, Skinner (1938) recounted how he modified the experimental environment, manipulandum, and procedures to produce responding that fit his goal of a response with a low but reliable operant level that could be automatically measured and would show rapid and reliable conditioning.

Given Skinner's account and my own experience with constructing levers, I infer that he tuned the lever in two ways. First, he changed the environment, the lever projection and shape, and 
its location to support the rat in easily and reliably manipulating it, especially when food was delivered in the area of the lever. At the same time, it is possible he 'detuned' the shape and amount of protrusion of the lever to encourage the rat to contact it repetitively with its paws rather than gnawing, holding, shaking, or nosing under it with a more obviously 'instinctive' topography. Recall that Skinner (1930) began his experimental career recording eating by requiring the rat to press open a flap to get access to a pellet of food. At the least it is clear the lever press is a manipulation response less overtly related to nosing for food than the first response he measured.

Despite the scarcity of formal statements about tuning, I believe the indirect evidence for it is overwhelming. First, there is the previously mentioned difficulty of building an apparatus from scratch that will elicit the same behavior as a traditional version in common use. I do not mean here the difficulties in getting food pellets to drop and micro switches to operate reliably. I mean the problem of getting the apparatus and procedure to readily elicit similar responding in individuals and species.

A second type of indirect evidence is the common difficulty researchers frequently have initially in replicating new phenomena from other laboratories. There is a vast laboratory lore that is critical to get a particular paradigm to work, lore that is embedded in the apparatus, procedure, experimental design, and training talents of the experimenter rather than in the conceptualization of the hypothesis, lore that is passed on from one generation of researchers to the next. To understand the critical aspects of a paradigm without this lore, it is usually necessary to explore the paradigm in a series of pilot studies. It is most helpful to actually visit a laboratory to see how they do it. This is a major reason that replication remains a critical component of behavioral science.

A third type of indirect evidence for the importance of tuning is the long process of getting a new combination of apparatus, procedure, reward, and species to work. In my experience of this process, the type of intruding misbehavior reported by Breland and Breland (1961) is more the rule than the exception in seeking to reinforce new behavior or similar behavior in a new species. The Breland's critical contribution was to label the phenomenon and carefully describe several examples. Occasionally, other researchers have incorporated an example of misbehavior into general-process accounts simply by giving it a label, as in the case of the omission effect in auto-shaping in which withholding reward when the pigeon pecks the predictive keylight only tenuously and momentarily disrupts pecking (Williams and Williams, 1969). Most frequently, though, experimenters confronted with misbehavior simply tune the apparatus and/or procedures to eliminate it (e.g. the implementation of a changeover delay to prevent response alternation in matching-law research, or Skinner's building a chimney around the hole into which his trained rat, Pliny, dropped a marble so the animal would not disrupt the trained responsechain by repeatedly mouthing the marble and retrieving it as it disappeared (Skinner, 1937; Skinner, 1975, pers. commun.).

When reminded of these types of evidence, most researchers acknowledge that tuning occurs. But, many dismiss its importance (as did a reviewer of this paper) with statements like; "Surely there is nothing wrong with fitting the apparatus to the sensory and motor equipment of the subject? After all, meaningful general laws of learning cannot be discovered by presenting visual stimuli to a blind animal". I certainly agree with the common sense of this position. But I believe it is also common sense to consider up front the relation of the apparatus, procedures, and conceptual analysis to a species' pre-organized sensory-motor structures and their relation to motivational processes and ecological function. Instead, experimenters still empirically tune their apparatus and procedures to enhance (and control) the vigor and reliability of responding. I believe this is why experimenters most often engage niche-related mechanisms haphazardly and without specific conceptual recognition (Timberlake, 1997). 


\subsection{Predictions of a niche-related approach about learning in general-process paradigms}

If systematic tuning of general-process learning paradigms has resulted in the engagement of nicherelated mechanisms, several testable predictions follow about the learned behaviors that emerge in traditional paradigms.

\subsubsection{Overdetermined responding}

The first prediction is that responding in a traditional general-process paradigm should be overdetermined. By overdetermined, I mean that there are significant causal mechanisms and support stimuli that influence the emergence of the learned behavior, in addition to the stimulus relations and response outcomes imposed by the experimenter. For example, it seem likely that components of naturally occurring foraging behavior, such as keypecking in pigeons and leverpressing and locomotion in rats, should not require strict response outcome contingencies to emerge. In fact, given the appropriate kind and timing of supporting CSs, niche-related foraging behaviors that vary with the timing and nature of the CS and the type of supporting stimuli should emerge readily under simple Pavlovian 'autoshaping' contingencies. Hearst and Jenkins (1974) provided documentation of these effects focused on pigeon key-pecking, and see Timberlake (Timberlake, 1994, 2001) for more complex predictions about how behavior should vary with the type of CS and US and the relation of the CS-US interval to underlying foraging search states.

Such niche-related perceptual-motor structures should not only emerge in behavior under CS-US contingencies, but should persist when not needed (Neuringer, 1970) or even when costly ( Williams and Williams, 1969). Niche-related perceptual-motor structure should also be engaged when reinforcing a response inadvertently produces temporal pairings between food and a niche-related CS. This emergence frequently can interfere with reinforced responding, as appears to occur in examples of misbehavior (Breland and Breland, 1961).

A final form of overdetermination can occur in the case of general appetitive behaviors, such as locomotion in rats. These general search behaviors should emerge under appropriate motivational conditions with little or no relation to food. For example in the case of efficient maze searching, Timberlake (1983a) reviewed and extended previous data showing that rats acquire straight-alley running in the absence of any food reward. Timberlake and White (1990) showed that rats acquired efficient search of a radial-arm maze in the absence of food, while Hoffman et al. (1999) and Timberlake et al. (1999) and Roche and Timberlake (1998) showed that rats still acquired arm-following even when the arms of a radial maze were placed flat on the floor so other search patterns were possible and more efficient.

\subsubsection{Reverse engineering}

A second general prediction from a niche-related analysis is that it should be possible to reverse engineer the procedures and apparatus of a generalprocess paradigm to discover information about the animal's niche-related capabilities. Reverse engineering usually refers to controlling the input of a system, examining the output, and attempting to infer the rules, mechanisms, and processes that produced it. For example, one takes a microprocessor or a software program and attempts to duplicate its structure and organization using only general knowledge about these objects combined with the results of testing the relation of inputs and outputs.

Reverse engineering is more efficient, though, given some idea of the components and processes that produced the result. Fortunately, based on fieldwork, the ethologists provided a starter kit of components in the form of perceptual-motor structures and their relation to each other and to motivational systems. My colleagues and I, based on our laboratory work, have proposed adding a sequence of motivational substates to each system in the form of repertoires of perceptual-motor modules. In the case of food, these substates include a general search mode related to finding food at a distance, a focal search mode related to finding proximal food, a handling/consuming mode related to ingestion, and a post-food focal search mode related to proximate area restricted search (please see Timberlake, 1983b, 1993, 1994, 1999, 2001; Timberlake and Lucas, 1989; Timber- 
lake and Silva, 1995). A more complete specification of components would also include aspects of neurophysiology and regulation.

Ethologists extensively used forms of reverse engineering to analyze the mechanisms underlying behavior by exploring the effects of modifying natural releasing stimuli to discover the critical elements controlling behavior. For example, Tinbergen and Perdeck (1950) analyzed the mechanisms controlling food begging in young gull chicks by observing their reaction to artificial changes in the characteristics of the spot on the bill. Hailman (1967) continued this work by exploring the effects of movement and experience on pecking.

Similar manipulations can be used in generalprocess paradigms to reverse engineer the determinants of behavior. For example, manipulating characteristics of the apparatus should reveal the environmental support involved in responding. Manipulating the nature of the CS and/or the US, and the temporal, spatial, and correlational relations between them, should clarify the perceptualmotor mechanisms and motivational processes involved (see Timberlake, 2001, for several examples).

A more qualitative form of reverse engineering is to inspect common apparatus and procedures and attempt to infer something of the perceptualmotor organization and ecology of the species associated with each one. For example, rat chambers and pigeon chambers differ in size, ambient lighting, type of flooring, presence of a hopper light, the location and form of manipulanda, and relative dependence on visual cues and finegrained visual stimuli. Without knowing what animals were run, one would be able to predict some of their perceptual-motor and processing characteristics

Similarly, inspection of established deprivation and feeding procedures provide the opportunity for inferences about species-typical foraging and regulation. For example, in rats a deprivation schedule usually consists of one feeding a day. Adaptation to such a schedule requires 5-7 days before a rat ingests sufficient food on a restricted schedule to maintain a stable body weight. This suggests a necessity to develop metabolic effi- ciency over several days (Woods and Strubbe, 1994) combined with anchoring anticipation of feeding to time of day (White and Timberlake, 1999). For smaller rodents, deprivation schedules consist of taking the food away $4-6 \mathrm{~h}$ before the experimental session occurs. Based on these procedures, we have several hints about differences in metabolic rates, storage capacities, and the likely frequency and size of meals in the wild.

\section{Toward integration of niche-related and general process approaches}

The view that researchers using general-process paradigms are actually studying niche-related learning has several advantages. It provides a conceptual and pragmatic basis for tuning apparatus and procedures to new repertoires, motivational systems, and species; it accounts for many of the puzzling phenomena in traditional learning paradigms (Timberlake and Lucas, 1989); and, it suggests reverse engineering of the current apparatus to discover characteristics of the species that have been induced through careful tuning. Perhaps, most importantly, it raises the possibility of developing a common ecological framework that can integrate learning and behavior in both laboratory paradigms and field circumstances, and that is sufficiently general to apply across species and sufficiently specific to account for the niche-related qualities of each one (see Timberlake and Lucas, 1989; Timberlake, 2001).

There is yet another advantage of taking a niche-related view that should have ramifications for the integration of the two approaches to learning. This advantage is that the specificity of the niche-related approach lends itself to facilitating connections between behavioral data and ongoing research in neurophysiology, evolution, and genetics. I am in no way downplaying the current successful connections among general process paradigms, neurophysiology, and genetics. I am arguing that considering the specificity of nicherelated aspects at the outset rather than inducing them solely on the basis of tuning can make such connections easier to develop and more secure. 


\subsection{Neurophysiology}

Despite Skinner's (Skinner, 1938) conclusion that there should be no conflict between behavioral and physiological levels of analysis, operant researchers often view neurophysiology as unnecessary and even unhelpful. I am sympathetic to the logic of the argument that studying operant conditioning at the behavioral level can be a self-contained enterprise with no need to deal with other levels of causal analysis. But, on pragmatic grounds this argument is less compelling to me than it used to be. Not only have many aspects of biology progressed remarkably, but if we agree that operant conditioning is based on niche-related learning, it seems shortsighted to ignore neurophysiological data and techniques relevant to the perceptual-motor organization and motivational processes involved in mechanisms, applications, and species comparisons. At the least such knowledge should facilitate the design of apparatus and procedures, and at best it should produce more complex conceptual and empirical analyses of behavior.

Current research indicates a good deal of separation and differentiation in the neurophysiological structures involved in learning, differences that should have ramifications for the design of experiments, including the selection of cues and responses, the timing and length of conditioning, and the choice of measures. For example, spatial learning in rats involves multiple structures in the brain (Pearce et al., 1998). The hippocampus appears critical for triangulation, but headings in a familiar environment can be maintained without a hippocampus, and parietal cortex appears important for other spatial functions. The bird song system also is highly organized in areas and pathways related to function. One area seems most related to song production, another to the ability to shape singing by listening, and another to acquiring new songs (DeVoogd and Szekely, 1998). Similar complexity appears to occur in aversive conditioning in rabbits. Conditioning of the nictitating membrane of the eye appears controlled by simple circuits in the cerebellum, while other aspects of avoidance conditioning are mediated by mid brain and ventral forebrain areas (Steinmetz and Thompson, 1991). In addition to their pragmatic importance in experimental design and treatment of disease, such specific differences speak to the evolution of learning, its ecological function, and behavioral aspects of its expression and function.

\subsection{Evolution}

Based on the argument that both learning and evolution represent selection by consequences (e.g. Skinner, 1966), there has developed a marked tendency for operant psychologists to view learning and evolution as highly analogous. The present view of learning as niche-related leads to a level of specificity that sharpens the differences between the components of learning and the components of evolution, making the analogy less inclusive and arresting. It can still prove heuristic, but it is difficult to see a close analogy between, say, different forms of response and different genes, or between the mechanisms of generalization and learning based variation on one hand and those of crossover, mutation, and sexual reproduction, on the other. Focusing on an abstract version of this analogy can easily lead to neglect of the specific relations that must be dealt with to adequately understand and predict behavior.

Recent work using genetic algorithms to model the relation of evolution and learning also speak to their separability (e.g. Littman, 1996). In these models evolution tends to facilitate the emergence of learning under conditions of rapid environmental change and restricted environmental and behavioral conditions for survival. Under the opposite conditions the evolution of learning is less likely. To complete the picture, learning can facilitate evolutionary change by exposing a population to new selection pressures, and it can also inhibit evolutionary change by suppressing the initial advantage of nonlearning solutions. Such models can provide a guide for predicting in which niche circumstances and species we are likely to find learning, and the forms it may take. 


\subsection{Genes and development}

Current advances in genetics have most of us scrambling to keep up. Producing yet another rip in my own tattered worldview, it is now well established that gene action is directly involved in changes in the behavior of adult organisms rather than simply affecting early development and growth and then shutting down. For example, genes activated by shifts in the external light cycle set in motion and participate in the cascade of physiological effects that produce the incremental, experience-based resetting of the rest-activity cycle (Rusak et al., 1990).

It is not surprising that many feel that the infatuation with genes has developed too fast. In an e-mail list discussion of the use of genetic knockouts (Animal Learning and Behavior list, May, 2000), Bob Brush asked, "What are they doing that's different from what Lashley did ... with brain lesions 70 years ago? What inference can be made about the function of a piece of (brain, genome, you choose) if you delete it? But what is even worse about the new genetic technology is that the genetic background in which the missing gene used to reside is ignored, and the missing piece is missing throughout development, not just removed from the adult, so that all of Lashley's inferential problems are compounded by the complex genetic-developmental-environmental interactions". But researchers using knockouts are now aware of this problem. As Michael Fanselow observed, “...temporally conditional and tissue selective transgenes and knockouts are around the corner. That means that not far off we will have the ability to do something like give an intraperitoneal injection and (1) selectively turn off the CA1 region of the hippocampus, (2) do it exactly when we want it done and then reverse the effects".

In the same discussion, biologist Daniella Bruner commented specifically on concerns about development, "Today 'genetics' for molecular biologists and geneticists truly means genetic structure and dynamics ... Gene expression is not just considered a cause but also a consequence of the animals' behavior and interaction with the environment". In a similar vein, population biologist
Michael Wade (pers. commun. May, 2000) pointed to work on models in population biology that could be used to test "...hypotheses about why the same individual at different times or different individuals at the same time respond differently to the same stimuli; why social or abiotic context matters more for some individuals and kinds of stimuli than others; why some kinds of tasks can be learned by some individuals but not other tasks or not by different individuals".

I agree that most geneticists screen altered animals on what they assume are abstract, general tests of behavior, whereas, by the arguments advanced above, they would be better off focusing on naturally occurring behavior because its biological specificity should be easier to pinpoint and, thus, its causation potentially easier to unravel. But it is also clear there will be interesting surprises that cast light on processes believed to be simpler. For example, Dubnau and Tully (1998) in research with Drosophila knockouts demonstrated that memory for a single shock is the product of a complex grouping of five or more storage processes, each process with different time courses of sensitivity to disruption, and even sensitivities to different disrupting stimuli. Similarly one could imagine that general differences in responding under schedules could be related to gene loci and neurophysiological processing. This in no way invalidates previous behavioral research. Neurophysiology and genetics are not an absorbing 'state' for behavioral research, but they can influence the precise design of schedules for particular species and purposes, which could, in turn, clarify the way genes are expressed. The genetic 'clock' will not turn back, but it will run more smoothly given better analysis of learning at the behavioral level.

\section{The ultimate form of integration}

There are obvious advantages to talking about the results of general-process paradigms in abstract terms that emphasize their generality. The experimental universe manipulated by the experimenter is usually well defined and the results are easy to communicate. As general instances of 
learning, results can be compared to and quickly become a part of a large body of regularities that appear lawful and reliable. General hypotheses can be tested; apparatus and procedures can be successfully adapted to applied settings and to different species. Unexpected results can acquire standing as labeled exceptions to our expectations.

Yet even in the most optimistic view of generalprocess learning, there can be considerable gain from taking the view that niche-related learning underlies all common general-process paradigms. Anomalies and classes of exceptions can be explained and predicted rather than only named and described; tuning for particular species and circumstances can be made easier and more effective; the connection between laboratory and field can be made more explicit; models of animals can be developed that should persist and grow with additional data; and the inter-connections with evolution, genetics, and neurophysiology can be facilitated.

Given their long-standing independence, neither approach requires the other, but there is potential gain from having both. It is certainly possible to do research using general-process paradigms without specifically acknowledging its niche-related aspects. Measures and manipulations are well defined, the stimuli and responses standardized, and the environment controlled. Experimenters can establish empirically reliable relations between manipulations and behavior that appear to generalize at some level across species and circumstances. Yet there is an excellent chance that the research could be more efficiently performed, the results made clearer, and the connection of learning to classic biological factors made easier simply by looking for the niche-related learning that occurs in a general-process paradigm. Further, a niche-related perspective raises important questions about the nature of empirical regularities, such as: why are similarities marked in some circumstances and tenuous in others; what sorts of tuning are essential to get regularities to emerge; what are their limits; how do these characteristics relate to the evolution and neurophysiology of the species (Timberlake, 1997)?
On the other side of the century-old divide, biologists have happily analyzed niche-related learning without using general process paradigms. They have tended to emphasize the importance of studying niche-related learning in natural circumstances rather than the unnatural cages and procedures of psychologists. But the evidence of a century supports the view that traditional generalprocess paradigms can provide an important means of clarifying the nature and components of niche-related learning that is not obvious or even available in a less controlled setting. Further, once researchers understand that paradigms are at least in part tuned to contact niche-related components, the data provided in such apparently unnatural environments actually becomes comparable to classic ethological work in clarifying the perceptual-motor structures and motivational processes of the animal, but with potentially greater control and more focus on the nature of the mechanism. The course of modern work on bird song learning is an excellent example of both the contributions and the liabilities of taking a primarily niche-related or primarily general paradigm approach. Both are important and at the same time, an obvious vote for integration.

A critical question for integration is how to conceive of learning as simultaneously general and niche-specific? The most popular answer among my psychologist colleagues is that nicherelated tuning provides the means by which learning is expressed, while general processes, such as the laws of association or the laws of outcome learning, produce the learning. On this basis, operant researchers typically argue that all outcome learning is based ultimately on the effects of the three-termed contingency. More cognitively oriented researchers tend to emphasize event related (causal) learning. They both agree that niche-related influences are a performance matter to be handled by appropriate adjustments of apparatus, procedures, and measures.

A major difficulty with this view is that once you begin to analyze the contribution of niche-related learning to the results of general-process paradigms, the easy division between tuning and learning, or between learning and performance, disappears. The specific niche-related components 
from perceptual filtering and response components to multiple repertoires, motivational systems, neurophysiology, and evolution cannot easily or appropriately be disentangled to reveal some general type of learning. An easy way to see this is through an illustration. Suppose a researcher believes there is a general causal computational capability present in all animals that will respond to the presentation of a stimulus reliably predicting reward by producing stimulus-tracking behavior. She decides to test this prediction in the pigeon. By taking advantage of experiments in the literature, she could create a set of experimental circumstances that would support the existence of a causal computational capability. However, based on the results of observation and manipulations designed to clarify pigeons' perceptual-motor structures and their spatially- and temporally-dependent repertories, she could equally as easily produce experiments that would contradict her hypothesis.

Does this mean that there is no universal causal computational capability? Not necessarily, what it means is that her hypothesis is specified incompletely. She needs to consider more specific examples of particular species in particular ecological circumstances and particular motivational states. A little thought should suggest that this kind of difficulty is a common occurrence in learning research. The only time we can make clean predictions is when we are familiar with a well-tuned paradigm (i.e. we have made good contact with niche-related components of learning) and we do not deviate too far from typical parameters. If we began to change things like the CS-US interval and the responses measured, we will be better advised to take a niche-related view.

\section{Conclusions}

The cumulative evidence appears strong that general-process learning paradigms are grounded in niche-related learning, and not just at the level of simple adjustments of procedure and apparatus to general sensory and motor capabilities of a species. We need to consider perceptual-motor structures and their often-specific relation to moti- vational systems and proximity-dependent repertoires and tactics. It is clear that general-process learning paradigms provide an abstract level of concepts with causal implications that are easy to manipulate and communicate. However, we cannot conduct a novel experiment at this level of abstraction and expect it to work reliably. Both philosophically and empirically, the experimenter's concepts and the niche-related qualities of the organisms need to be integrated in a common study of learning. Determining exactly what forms this integration should take is an ongoing task that will require experimental analysis, as well as conceptual clarification, of what niche-related learning contributes and exactly what constitutes general laws and processes.

Whatever the ultimate form of integration, several important advantages will remain to taking a niche-related view of the results of general-process learning paradigms. A niche-related approach can, apply to and make use of data from both laboratory and field experiments, thereby improving our understanding of learning in both the contexts; facilitate the process of tuning in controlled tasks and at the same time call attention to the information that procedures and apparatus contain about the subject's ecological niche; generate predictions about the phenomena that characterize general-process paradigms as well as predict and account for classic anomalies; provide a more secure and productive path for integration of the behavioral study of learning with neurophysiology, evolution, genetics, and development.

\section{Uncited reference}

Rescorla and Wagner (1972).

\section{Acknowledgements}

Preparation of this manuscript was supported by NSF Grant IBN \# 17175 and NIDA Grant \# 11092. Thanks to Peter Killeen, Armando Machado, Allen Neuringer and an unidentified reviewer for useful feedback, and to Oregon Health Sciences University and Reed College for hosting me. 


\section{References}

Balsam, P., Deich, J., Hirose, R., 1993. The roles of experience in the transition from dependent to independent feeding in ring doves. In: Turkewitz, G. (Ed.), Developmental Psychobiology. New York Academy of Sciences, New York, pp. 16-36.

Barber, L., 1980. The Heyday of Natural History. Doubleday and Co, Garden City, NJ.

Breland, K., Breland, M., 1961. The misbehavior of organisms. Am. Psychol. 16, 681-684.

Bingman, V.P., Jones, T.J., 1994. Sun compass-based spatial learning impaired in homing pigeons with hippocampal lesions. J. Neurosci. 14, 6687-6694.

Calhoun, J.B., 1962. The Ecology and Sociology of the Norway Rat. U.S. Department of Health, Education, and Welfare, Bethesda, MD.

DeVoogd, T.J., Szekely, T., 1998. Causes of avian song: Using neurobiology to integrate proximate and ultimate levels of analysis. In: Balda, R.P., Pepperberg, I.M., Kamil, A.C. (Eds.), Animal Cognition in Nature. Academic Press, San Diego, pp. 337-380.

Dubnau, J., Tully, T., 1998. Gene discovery in Drosophila: new insights for learning and memory. Ann. Rev. Neurosci. 21, 407-444.

Eiseley, L., 1961. Darwin's Century. Doubleday, New York.

Galef, B.G., 1988. Evolution and learning before Thorndike: a forgotten epoch in the history of behavioral research. In: Bolles, R.C., Beecher, M.D. (Eds.), Evolution and Learning. Erlbaum, Hillsdale, NJ, pp. 39-58.

Gallistel, C.R., 1990. The Organization of Learning. MIT Press, Cambridge, MA.

Griffin, D.R., 1981. The Question of Animal Awareness: Evolutionary Continuity of Mental Experience. Rockefeller University Press, New York.

Hailman, J.P., 1967. The ontogeny of an instinct: the pecking response in chicks of the laughing gull (Laurus Artricilla L.) and related species. Behaviour 14, 1-159.

Hearst, E., Jenkins, H.M., 1974. Signtracking: The StimulusReinforcer Relation and Directed Action. Psychonomic Society, Austin, TX.

Hess, E.H., 1964. Imprinting in birds. Science 146, 1128-1139.

Hoffman, H.S., 1977. Experimental analysis of imprinting and its behavioral effects. Psychol. Learn. Motiv. 12, 1-37.

Hoffman, C.M., Timberlake, W., Leffel, J., Gont, R., 1999. How is radial arm maze behavior related to locomotor search tactics? Anim. Learn. Behav. 27, 426-444.

Hull, C.L., 1943. Principles of Behavior. Appleton-CenturyCrofts, New York.

Huxley, J., 1914. The courtship habits of the Great Crested Grebe (Podiceps cristatus); with an addition to the theory of sexual selection. Proc. Zool. Soc. Lond. 35, 491-562.

Kroodsma, D.E., 1988. Contrasting styles of song development and their consequences among passerine birds. In: Bolles, R.C., Beecher, M.D. (Eds.), Evolution and Learning. Erlbaum, Hillsdale, NJ, pp. 157-184.
Krane, R.V., Wagner, A.R., 1975. Taste aversion learning with a delayed shock US: implications for the "generality of the laws of learning". J. Comp. Physiol. Psych. 88, $882-889$.

Lashley, K.S., 1950. In search of the engram. Symp. Soc. Exp. Biol. 4, 454-482.

Lehrman, D.S., 1953. Problems raised by instinct theories. Q. Rev. Biol. 28, 337-365.

Littman, M., 1996. Simulations combining evolution and learning. In: Belew, R.K., Mitchell, M. (Eds.), Adaptive Individuals in Evolving Populations. Addison-Wesley, New York, pp. 465-477.

Logue, A.W., 1979. Taste aversion and the generality of the laws of learning. Psychol. Bull. 86, 276-296.

Lorenz, K.Z., 1937. The companion in the bird's world. Auk 54, 245-273.

Lorenz, K.Z., 1965. The Evolution and Modification of Behavior. University of Chicago Press, Chicago, IL.

Lubbock, J., 1882. Ants, Bees, and Wasps. Kegan, Paul and Trench, London.

Moore, B.R., 1973. The role of directed Pavlovian reactions in simple instrumental learning in the pigeon. In: Hinde, R.A., Stevenson-Hinde, J. (Eds.), Constraints on Learning: Limitations and Predispositions. Academic Press, New York, pp. 159-188.

Moore, B.R., Stuttard, S., 1979. Dr. Guthrie and Felis domesticus: or, tripping over the cat. Science 205, 1031-1033.

Morgan, C.L., 1895. An Introduction to Comparative Psychology. Walter Scott, London.

Muenzinger, K.F., 1928. Plasticity and mechanization of the problem box habit in guinea pigs. J. Comp. Psychol. 8, 45-69.

Neuringer, A.J., 1970. Many responses per food reward with free food present. Science 169, 503-504.

Olds, J., Milner, P., 1954. Positive reinforcement produced by electrical stimulation of septal area and other regions of rat brain. J. Comp. Physiol. Psychol. 47, 419-427.

Pavlov, I.P., 1927. Conditioned Reflexes. Oxford University Press, London G.V. Anrep, translator.

Pearce, J.M., 1997. Animal Learning and Cognition: An Introduction, second ed. Psychology Press, East Sussex, UK.

Pearce, J.M., Roberts, A.D.L., Good, M., 1998. Hippocampal lesions disrupt navigation based on cognitive maps but not heading vectors. Nature 396, 75-77.

Peterson, G.B., Ackil, J.E., Frommer, G.P., Hearst, E.S., 1972. Conditioned approach and contact behavior toward signals for food and brain stimulation reinforcement. Science 177, 1009-1011.

Rescorla, R.A., Wagner, A.R., 1972. A theory of Pavlovian conditioning: variations in the effectiveness of reinforcement and nonreinforcement. In: Black, A.H., Prokasy, W.F. (Eds.), Classical Conditioning II: Current Research and Theory. Appleton-Century-Crofts, New York, pp. 6499.

Roberts, W.A., 1997. Principles of Animal Cognition. McGraw-Hill, Boston. 
Roche, J.P., Timberlake, W., 1998. Orientation and efficiency: The influence of artificial paths and landmarks on the foraging of Norway rats (Rattus norvegicus). Anim.Learn. Behav 28, 465-490.

Rusak, B., Robertson, H.A., Wisden, W., Hunt, S.P., 1990. Light-pulses that shift rhythms induce gene-expression in the suprachiasmatic nucleus. Science 248, 1237-1240.

Selous, E., 1931. Thought Transference (or what?) in Birds. Constable and Company, London.

Shettleworth, S.J., 1998. Cognition, Evolution, and Behavior. Oxford University Press, New York.

Skinner, B.F., 1930. On the conditions of elicitation of certain eating reflexes. Proc. Natl. Acad. Sci. 16, 433-438.

Skinner, B.F., 1937. Rat works slot machine for a living. Life, pp. $80-81$.

Skinner, B.F., 1938. The Behavior of Organisms. AppletonCentury-Crofts, New York.

Skinner, B.F., 1953. Science and Human Behavior. AppletonCentury-Crofts, New York.

Skinner, B.F., 1959. A case history in the scientific method. In: Koch, S. (Ed.), Psychology: A Study of a Science, vol. 2. McGraw-Hill, New York, pp. 359-379.

Skinner, B.F., 1966. The phylogeny and ontogeny of behavior. Science 153, 1204-1213.

Small, W.S., 1900. An experimental study of the mental processes of the rat. Am. J. Psychol. 11, 133-165.

Spalding, D.A., 1872. On instinct. Nature 6, 485-486.

Steinmetz, J.E., Thompson, R.F., 1991. Brain substrates of aversive classical conditioning. In: Madden, J. IV (Ed.), Neurobiology of Learning, Emotion and Affect. Raven Press, New York, pp. 97-120.

Stokes, P., Balsam, P.D., 1991. Effects of reinforcing preselected approximations on the topography of the rat's bar press. J. Exp. Anal. Behav. 55, 213-231.

Thorndike, E.L., 1911. Animal Intelligence. Macmillan, New York.

Timberlake, W., 1983a. Appetitive structure and straight alley running. In: Mellgren, R. (Ed.), Animal Cognition and Behavior. North Holland Press, Amsterdam, pp. 165-222.

Timberlake, W., 1983b. The functional organization of appetitive behavior: behavior systems and learning. In: Zeiler, M.D., Harzem, P. (Eds.), Advances in the Analysis of Behavior, Biological Factors in Learning, vol. 3. Wiley, Chichester, pp. 177-221.

Timberlake, W., 1993. Behavior systems and reinforcement: an integrative approach. J. Exp. Anal. Behav. 60, 105-128.

Timberlake, W., 1994. Behavior systems, associationism, and Pavlovian conditioning. Psychon. Bull. Rev. 1, 405-420.

Timberlake, W., 1997. An animal-centered, causal-system approach to the understanding and control of behavior. Appl. Anim. Behav. Sci. 53, 107-129.
Timberlake, W., 1999. Biological behaviorism. In: O’Donohue, W., Kitchener, R. (Eds.), Handbook of Behaviorism. Academic Press, San Diego, pp. 243-284.

Timberlake, W., 2001. Motivational modes in behavior systems. In: Mowrer, R.R., Klein, S.B. (Eds.), Handbook of Contemporary Learning Theories. Erlbuam, Hillsdale, NJ, pp. 155-209.

Timberlake, W., Hoffman, C.M., 1998. Comparative analyses of learning. In: Greenberg, G., Haraway, M. (Eds.), Comparative Psychology: A Casebook. Garland Publishing, New York, pp. 553-564.

Timberlake, W., Leffel, J., Hoffman, C.M., 1999. Stimulus control and function of arm following by rats on a radialarm floor maze. Anim. Learn. Behav. 27, 445-460.

Timberlake, W., Lucas, G.A., 1985. The basis of superstitious behavior: chance contingency, stimulus substitution, or appetitive behavior? J. Exp. Anal. Behav. 44, 279-299.

Timberlake, W., Lucas, G.A., 1989. Behavior systems and learning: From misbehavior to general principles. In: Klein, S.B., Mowrer, R.R. (Eds.), Contemporary Learning Theories: Instrumental Conditioning Theory and The Impact of Biological Constraints on Learning. Erlbaum, Hillsdale, NJ, pp. 237-275.

Timberlake, W., Silva, K.M., 1995. Appetitive behavior in ethology, psychology, and behavior systems. In: Thompson, N. (Ed.), Perspectives in Ethology. Plenum Press, New York, pp. 211-253.

Timberlake, W., White, W., 1990. Winning isn't everything: rats need only food deprivation not food reward to traverse a radial arm maze efficiently. Learn. Motiv. 21, $153-163$.

Tinbergen, N., 1951. The Study of Instinct. Clarendon Press, Oxford, UK.

Tinbergen, N., Perdeck, A.C., 1950. On the stimulus situation releasing the begging response in the newly hatched herring gull chick (Larus argentatus Pont.). Behaviour 3, 1-39.

van Kampen, H.S., de Vos, G.J., 1995. A study of blocking and overshadowing in filial imprinting. Q. J. Exp. Psych.: Comp. Physiol. Psych. 48B, 346-356.

Vos, D.R., 1995. The development of sex recognition in the zebra finch. PhD. Thesis, University of Groningen, The Netherlands.

Wasserman, E.A., 1993. Comparative cognition: beginning the second century of the study of animal intelligence. Psychol. Bull. 113, 211-228.

White, W., Timberlake, W., 1999. Meal-engendered circadian ensuing activity in rats. Physiol. Behav. 65, 625-642.

Williams, D.R., Williams, H., 1969. Auto-maintenance in the pigeon: Sustained pecking despite contingent non-reinforcement. J. Exp. Anal. Behav. 12, 511-520.

Woods, S.C., Strubbe, J.H., 1994. The psychobiology of meals. Psychon. Bull. Rev. 1, 141-155. 